\title{
VIEWPOINT
}

\section{Delayed reemergence of consciousness in survivors of severe COVID-19}

\author{
Brian L. Edlow' ${ }^{1}$ Jan Claassen², Jonathan D. Victor ${ }^{3}$, Emery N. Brown ${ }^{4,5}$ and Nicholas D. Schiff ${ }^{*}$
}

() 2020 Springer Science+Business Media, LLC, part of Springer Nature and Neurocritical Care Society

Survivors of coronavirus disease 2019 (COVID-19) around the world are coming off ventilators every day, having overcome multi-organ system failure and weeks sedated, paralyzed, and isolated from family in the intensive care unit (ICU). The triumph of survival, for those who recover consciousness, is celebrated with nurses, physicians, respiratory therapists and the multitudes of hospital staff who care for patients with COVID-19. The long journey to inpatient rehabilitation, and ultimately home, begins.

Yet many COVID-19 survivors have not recovered consciousness. They remain unresponsive and bedbound, persistently disconnected from their environment. As each day passes after removing the endotracheal tube and weaning sedation, a patient's inability to regain consciousness becomes more disconcerting to families and clinicians. Prolonged alterations of consciousness ranging from coma to delirium have consistently been reported in patients with severe COVID-19 [1-4], but epidemiological estimates of incidence and prevalence are not yet available. Altered consciousness in patients with severe COVID-19 was the most common reason for neurological consultation at our medical centers in New York and Boston during the COVID-19 surge in the Spring of 2020 [5]. Although we tried to use every diagnostic and prognostic tool at our disposal-the neurological exam, electroencephalography (EEG), computed tomography (CT), and magnetic resonance imaging (MRI) - resource limitations and concerns about the exposure to health care workers and other patients constrained our ability to use these tools. Nearly every question about how severe

\footnotetext{
${ }^{*}$ Correspondence: nds2001@med.cornell.edu

${ }^{3}$ Feil Family Brain and Mind Research Institute, Weill Cornell Medical Center, New York, NY, USA

Full list of author information is available at the end of the article
}

COVID-19 affects the brain thus remains incompletely answered [6].

Sedation likely contributes to prolonged unconsciousness, given that sustained, high levels of sedation are often needed to ensure ventilator synchrony in COVID19 patients with acute respiratory distress syndrome (ARDS) $[7,8]$. The adverse effects of sedatives on higherorder cognition are well established $[9,10]$, but how sustained, high doses of sedatives affect the reemergence of consciousness itself is unknown. Moreover, some sedative agents may predispose to more enduring depression of consciousness [11]. After unprecedented drug combinations, dosing regimes, and durations of sedation, often in the setting of hypoxia, metabolic derangements, and impaired drug clearance due to renal or liver failure, the human brain's ability to reintegrate its neural networks is now being tested in ICUs around the world.

Addressing the new challenges posed by the COVID19 pandemic in a coordinated fashion is likely to inform our understanding of the mechanistic basis of consciousness. As patients emerge from weeks in anesthetic coma, circuits must retune their electrical firing properties; synapses must reestablish their neurotransmitter expression profiles and anatomic specificity [11]. Only with the intricate orchestration of ensembles of networks can the brain regain its full repertoire of integrative cognitive functions. Importantly, recent evidence demonstrates that when brain structure is well preserved (as it is in many slow-to-recover COVID-19 patients), even prolonged coma for several weeks after cardiac arrest may yield independent outcomes [12]. Given uncertainty about the natural history of recovery from COVID-19, it is crucial to better understand the prognostic potential of COVID19 patients who are slow to recover consciousness.

As the resilience of the human brain is tested by sustained, high levels of sedation, there is also growing recognition that patients with severe COVID-19 are at risk

\section{6 Springer}


for particular forms of brain injury. The pathophysiologic mechanisms of brain injury in severe COVID-19 appear to include hypoxia, inflammation, hypercoagulability [3], endothelial infection by the virus (SARS-CoV-2) [13], and possibly direct infection of the central nervous system by SARS-CoV-2 [14]. The clinical manifestations [1, 3], EEG characteristics $[1,15], \mathrm{CT} / \mathrm{MRI}$ findings $[3,16,17]$ and histopathological hallmarks $[18,19]$ of these injurious processes, including elevated stroke risk, are just beginning to be recognized.

As we learn the lessons from the first global wave of COVID-19 and prepare for future battles with this disease, protecting brain function should be at the top of the list of priorities for the medical and research communities. The need for high levels of sedation is compelling in the sickest COVID-19 patients, whose pulmonary function is so tenuous that a single cough could cause ventilator dyssynchrony and hypoxia. But there may be more targeted ways for us to administer sedation and control pain in the ICU $[20,21]$-approaches that might also utilize limited resources more effectively.

We need a comprehensive understanding of a critical tradeoff: deeper sedation facilitates treatment of ARDS, but excessive sedation may delay recovery of consciousness and impair neurologic recovery. Ideally, clinicians would use EEG guidance to titrate sedatives to maintain ventilator synchrony while allowing brain function to persist. For example, with propofol, the typical EEG signature of unconsciousness is slow-delta oscillations $(0.1-4 \mathrm{~Hz})$ [11]. Hence, the ideal propofol dose would be the one that sustained this pattern at the lowest possible infusion rate. For the majority of COVID-19 patients around the world, even at well-resourced hospitals, it is not feasible to perform continuous EEG monitoring throughout a patient's entire ICU stay. The neurological examination is insufficient for guiding sedative dosing, because comatose patients who are appropriately sedated (e.g. slow-delta oscillations) appear identical on examination to those who are oversedated (e.g. burst suppression). With the duration of sedation approaching weeks, and in some severe COVID-19 patients more than a month [5, 17], long periods of time elapse during which ICU clinicians make well-intentioned decisions about sedation without EEG feedback to guide them.

There is thus an urgent need for a coordinated effort to develop optimized sedation regimens and novel neuroprotective strategies. We must address fundamental gaps in knowledge about how COVID-19 affects the brain, and we need to identify optimal oxygenation thresholds, blood pressure thresholds, and immunomodulatory therapies that might prevent or treat the diverse endotypes of brain injury associated with COVID-19. Patients should have periodic EEG monitoring to prevent prolonged oversedation; the frequency and duration of such monitoring can be determined by local resources and expertise to balance risks to health care workers.

To improve the accuracy of prognostication in patients with disorders of consciousness after severe COVID-19, we need to elucidate the relative utility of EEG, head CT, conventional MRI, and advanced imaging techniques such as functional MRI [17], magnetic resonance spectroscopy [22], and diffusion tensor imaging [23, 24]. Comprehensive safety precautions to protect hospital staff and other patients must be implemented before transporting a patient with severe COVID-19 from the ICU to the MRI scanner. If such safety measures are in place, we support a multimodal approach to prognostication that integrates data from complementary behavioral, electrophysiologic, and imaging tests, consistent with Guidelines endorsed by the American Academy of Neurology, American Congress of Rehabilitation Medicine, National Institute on Disability, Independent Living and Rehabilitation Research [25], and the European Academy of Neurology [26]. Moreover, we recommend that prognoses be based upon the consensus opinion of multidisciplinary specialists with a broad range of expertise [5], including clinicians from neurocritical care, neuroinfectious diseases, epilepsy, neuroradiology, pharmacology, and physical medicine and rehabilitation.

Given the importance of meeting these new challenges with data $[27,28]$, we applaud recent initiatives to investigate coma recovery by the Neurocritical Care Society's Curing Coma Campaign [29], as well as international initiatives focused on patients with severe COVID-19, such as the Global Consortium Study of Neurological Dysfunction in COVID-19 (GCS-NeuroCOVID) [30], the CoroNerve Study Group [4], and the James S. McDonnell Foundation's COVID-19 Recovery of Consciousness Consortium. These ongoing studies aim to answer four central questions: (1) Which sedation regimens optimize treatment of ARDS but least associate with prolonged disorders of consciousness? (2) What factors cause prolonged impairment of consciousness after severe COVID-19 in the absence of structural brain injuries? (3) Which electrophysiologic and neuroimaging tools differentiate reversible from irreversible causes of altered consciousness? (4) Which patients with disorders of consciousness after severe COVID-19 are likely to recover consciousness, communication, and functional independence? Only with a comprehensive and coordinated international effort can we begin to answer these questions and improve outcomes for patients who survive severe COVID-19. 


\section{Author details}

${ }^{1}$ Center for Neurotechnology and Neurorecovery, Department of Neurology,

Massachusetts General Hospital and Harvard Medical School, Boston, MA, USA

${ }^{2}$ Department of Neurology, Columbia University, New York, NY, USA. ${ }^{3}$ Feil

Family Brain and Mind Research Institute, Weill Cornell Medical Center, New York, NY, USA. ${ }^{4}$ Department of Anesthesia, Critical Care and Pain Medicine, Massachusetts General Hospital and Harvard Medical School, Boston, MA, USA.

${ }^{5}$ Picower Institute, Massachusetts Institute of Technology, Cambridge, MA, USA.

\section{Author contributions}

All authors contributed to the conception, writing and editing of this editorial.

\section{Source of Support}

We are grateful for support from the James S. McDonnell Foundation COVID19 Recovery of Consciousness Consortium.

\section{Conflicts of interest}

None.

\section{Publisher's Note}

Springer Nature remains neutral with regard to jurisdictional claims in published maps and institutional affiliations.

Received: 4 August 2020 Accepted: 13 October 2020

Published online: 10 November 2020

\section{References}

1. Helms J, Kremer S, Merdji H, et al. Neurologic features in severe SARSCoV-2 infection. N Engl J Med. 2020;382:2268-70.

2. Mao L, Jin H, Wang M, Hu Y, Chen S, He Q, Miao X. Neurologic manifestations of hospitalized patients with coronavirus disease 2019 in Wuhan, China. JAMA Neurol. 2020;77(6):683-90.

3. Paterson RW, Brown RL, Benjamin L, et al. The emerging spectrum of COVID-19 neurology: clinical, radiological and laboratory findings. Brain. 2020;143:3104-20.

4. Varatharaj A, Thomas N, Ellul MA, et al. Neurological and neuropsychiatric complications of COVID-19 in 153 patients: a UK-wide surveillance study. Lancet Psychiatry. 2020;7(10):875-82.

5. Waldman GJ, Thakur KT, Der Nigoghossian C, et al. Multidisciplinary guidance to manage comatose patients with severe COVID-19. Ann Neurol. 2020;88:653-55.

6. Needham EJ, Chou SH, Coles AJ, et al. Neurological implications of COVID-19 infections. Neurocrit Care. 2020;32:667-71.

7. Hanidziar D, Bittner E. Sedation of mechanically ventilated COVID19 patients: challenges and special considerations. Anesth Analg. 2020;131:e40-1.

8. Bhatraju PK, Ghassemieh BJ, Nichols M, et al. Covid-19 in critically III patients in the seattle region — case series. N Engl J Med. 2020;382:2012-22.

9. Moller JT, Cluitmans P, Rasmussen LS, et al. Long-term postoperative cognitive dysfunction in the elderly ISPOCD1 study ISPOCD investigators. International study of post-operative cognitive dysfunction. Lancet. 1998;351:857-61.

10. Porhomayon J, El-Solh AA, Adlparvar G, et al. Impact of sedation on cognitive function in mechanically ventilated patients. Lung. 2016;194:43-52.
11. Brown EN, Lydic R, Schiff ND. General anesthesia, sleep, and coma. N Engl J Med. 2010;363:2638-50.

12. Forgacs PB, Devinsky O, Schiff ND. Independent functional outcomes after prolonged coma following cardiac arrest: a mechanistic hypothesis. Ann Neurol. 2020;87:618-32.

13. Varga Z, Flammer AJ, Steiger P, et al. Endothelial cell infection and endotheliitis in COVID-19. Lancet. 2020;395:1417-8.

14. Paniz-Mondolfi A, Bryce C, Grimes Z, et al. Central nervous system involvement by severe acute respiratory syndrome coronavirus-2 (SARSCoV-2). J Med Virol. 2020;92:699-702.

15. Sethi NK. EEG during the COVID-19 pandemic: what remains the same and what is different. Clin Neurophysiol. 2020;131:1462.

16. Kandemirli SG, Dogan L, Sarikaya ZT, et al. Brain MRI Findings in patients in the intensive care unit with COVID-19 infection. Radiology. 2020;297:E232-5

17. Fischer $D$, Threlkeld ZD, Bodien $Y G$, et al. Intact brain network function in an unresponsive patient with COVID-19. Ann Neurol. 2020;88(4):851-4.

18. Schaller T, Hirschbuhl $K$, Burkhardt $K$, et al. Postmortem examination of patients with COVID-19. JAMA. 2020;323:2518-20.

19. Solomon IH, Normandin E, Bhattacharyya S, et al. Neuropathological features of Covid-19. N Engl J Med. 2020;383:989-92.

20. Brown EN, Pavone KJ, Naranjo M. Multimodal general anesthesia: theory and practice. Anesth Analg. 2018;127:1246-58.

21. Devlin JW, Skrobik Y, Gelinas C, et al. Clinical practice guidelines for the prevention and management of pain, agitation/sedation, delirium, immobility, and sleep disruption in adult patients in the ICU. Crit Care Med. 2018;46:e825-73.

22. Rapalino O, Weerasekera A, Moum SJ, et al. Brain MR spectroscopic findings in three consecutive COVID-19 patients: Preliminary observations. medRxiv. 2020. https://doi.org/10.1101/2020.06.10.20122465.

23. Newcombe V, Spindler I, Das T, et al. Neuroanatomical substrates of generalized brain dysfunction in COVID-19. Intensive Care Med. 2020. https:// doi.org/10.17863/CAM.57001.

24. Lu Y, Li X, Geng D, et al. Cerebral micro-structural changes in COVID-19 patients-an MRI-based 3-month follow-up study. EClinicalMedicine. 2020;25:100484.

25. Giacino JT, Katz DI, Schiff ND, et al. Practice guideline update recommendations summary: Disorders of consciousness: report of the guideline development, dissemination, and implementation subcommittee of the American Academy of Neurology; the American Congress of Rehabilitation Medicine; and the National Institute on Disability, Independent Living, and Rehabilitation Research. Neurology. 2018;91:450-60.

26. Kondziella D, Bender A, Diserens K, et al. European academy of neurology guideline on the diagnosis of coma and other disorders of consciousness. Eur J Neurol. 2020;27(5):741-56.

27. Winkler AS, Knauss S, Schmutzhard E, et al. A call for a global COVID-19 neuro research coalition. Lancet Neurol. 2020;19:482-4.

28. Moro E, Deuschl G, de Visser M, et al. A call from the European Academy of Neurology on COVID-19. Lancet Neurol. 2020;19:482.

29. Provencio JJ, Hemphill JC, Claassen J, et al. The curing coma campaign: framing initial scientific challenges-proceedings of the first curing coma campaign scientific advisory council meeting. Neurocrit Care. 2020;33:1-12.

30. Frontera J, Mainali S, Fink EL, et al. Global consortium study of neurological dysfunction in COVID-19 (GCS-NeuroCOVID): study design and rationale. Neurocrit Care. 2020;33:25-34. 